\title{
REFLEXÃO SOBRE A UTILIZAÇÃO CRIATIVA DOS RECURSOS TECNOLÓGICOS
}

\author{
REFLEXIÓN SOBRE EL USO CREATIVO DE LOS RECURSOS \\ TECNOLÓGICOS
}

REFLECTION ON THE CREATIVE USE OF TECHNOLOGICAL RESOURCES

\author{
Priscilla Aparecida Santana BITTENCOURT ${ }^{1}$ \\ João Pedro ALBINO ${ }^{2}$
}

RESUMO: Este estudo apresenta uma parte da pesquisa realizada no curso de mestrado do programa de pós-graduação em mídia e tecnologia na FAAC, Unesp de Bauru/SP, trata-se de uma reflexão sobre a utilização criativa dos recursos tecnológicos de maneira didática, explorando o uso das mídias digitais nas escolas. O estudo teve o intuito de realizar um estudo de caso nas escolas de ensino médio da cidade de Bauru, e verificar qual a situação do uso das mídias digitais no processo de ensino-aprendizagem, tanto na visão do aluno como na visão do professor.

PALAVRAS-CHAVE: Mídias digitais. Educação. Ensino-aprendizagem. Tecnologias.

RESUMEN: Este estudio presenta una parte de la investigación realizada en el curso de maestría del programa de pos-graduación en medios y tecnología en la FAAC Unesp de Bauru / SP, se trata de una reflexión sobre la utilización creativa de los recursos tecnológicos de manera didáctica, explorando el uso de los medios digitales en las escuelas. El estudio ha tenido el propósito de realizar un estudio de caso en las escuelas de enseñanza media de la ciudad de Bauru, y verificar cuál es la situación del uso de los medios digitales en el proceso de enseñanza-aprendizaje, tanto en la visión del alumno como en la visión del profesor.

PALABRAS-CLAVE: Medios digitales. Educación. Enseñanza-aprendizaje.

Tecnologías.

ABSTRACT: This study presents a part of the research carried out in the masters course of the postgraduate program in media and technology at FAAC Unesp of Bauru/SP, it is a reflection on the creative use of technological resources in didactic way, exploring the use of digital media in schools. The purpose of the study was to carry out a case study in the high schools of the city of Bauru and to verify the situation

${ }^{1}$ Universidade Estadual Paulista Júlio de Mesquita Filho (UNESP), Faculdade de Ciências de Bauru, Bauru - SP - Brasil. Doutoranda pelo Programa de Pós-graduação em Mídia e Tecnologia, Bolsista capes. Email: priscillasant@gmail.com

${ }^{2}$ Universidade Estadual Paulista Júlio de Mesquita Filho (UNESP), Faculdade de Ciências de Bauru, Bauru - SP - Brasil. Professor do Departamento de Computação. Email: jpalbino@fc.unesp.br 
of the use of digital media in the teaching-learning process, both in the student's view and in the teacher's view.

KEYWORDS: Digital media. Education. Teaching-learning. Technologies.

\section{Introdução}

O cenário desta pesquisa leva em consideração que a internet tem influenciado no modus operandi do nativo digital, e tem como intuito refletir como os adolescentes acima de 14 anos de idade usam a tecnologia na escola, além de refletir sobre a ótica do professor em relação ao uso da tecnologia em sala de aula.

Conforme afirma Prfromm Netto (p. 67), é bastante preocupante o despreparo de parte considerável da população brasileira para enfrentar os desafios e as perplexidades que estes novíssimos tempos estão impondo à humanidade.

Segundo Castells (1999, p. 21), "uma revolução tecnológica concentrada nas tecnologias da informação está remodelando a base material da sociedade em ritmo acelerado".

Basta olhar ao redor e percebe-se que esse ritmo acelerado que Castells fala está presente em quase todos os lugares. As pessoas não desligam mais os smartphones e o wi-fi, parece que possuem uma certa necessidade de estarem conectadas ao mundo virtual a todo instante.

Esta pesquisa foi realizada em duas escolas da cidade de Bauru, interior do estado de São Paulo, sendo uma pública e outra particular.

Considera-se que a escola pública escolhida é uma boa escola e de referência, comparada às demais escolas públicas da cidade de Bauru. Já a escola particular escolhida, comparada com as demais escolas particulares que existem na cidade, é considerada uma escola mediana.

Em uma pesquisa sobre as TIC's em sala de aula, os autores realizaram um estudo com a rede pública da cidade de Piracicaba/SP, e segundo eles afirmam:

Questionados sobre a importância do uso de TIC, 49\% dos professores acreditam que o uso de TIC nos espaços escolares é muito importante, $39 \%$ acha importante, $11 \%$ julga pouco importante e $1 \%$ acredita que o uso de TIC nas escolas é irrelevante (DARIDO DA CUNHA; BIZELLI, 2016, p. 285). 
Segundo os autores Rocha e Moreira (2017), que realizaram uma pesquisa com os professores em seu trabalho, "a disponibilização das novas tecnologias em diferentes tempos e espaços facilita o acesso dos alunos aos mais diversos temas, e isso contribui para o enriquecimento das aulas".

Conforme Martino (2014, p. 204), a tecnologia "mais do que um suporte para mensagens, é um elemento decisivo na formação da mente, dos modos de sentir, perceber e compreender a realidade"

Para Perrenoud (1999), a melhoria do processo de aprendizagem e a familiarização dos alunos com as novas mídias digitais exigem a necessidade de se desenvolver competências. Estabelecendo que uma destas competências é o uso da mídia digital na educação, Perrenoud (1999) sugere que em situações-problema, os professores utilizem, de preferência, softwares didáticos ou aplicativos que auxiliem diariamente as mais diversas tarefas intelectuais.

O instrumento de coleta utilizado neste estudo foi um questionário estruturado e específico para cada grupo de participantes; as questões que compõem o questionário aplicado foram desenvolvidas pela autora no decorrer deste estudo.

Os dados foram coletados por meio de questionários com perguntas estruturadas e predefinidas (respostas únicas ou múltiplas). Estes questionários foram de autopreenchimento e abrangeram assuntos de mídias digitais e seu uso no dia-a-dia.

O público-alvo da pesquisa é composto por uma escola pública (estadual) e uma escola particular, e as questões foram aplicadas nos níveis de ensino médio para o $1^{\circ}$ ano do Ensino Médio (EM-1) e $3^{\circ}$ ano do Ensino Médio (EM-3).

Também compõem o público-alvo da pesquisa os alunos matriculados e os professores envolvidos com as turmas dos níveis de ensino considerados na pesquisa.

Esta pesquisa teve como finalidade realizar um estudo de caso nas escolas de ensino médio da cidade de Bauru, e verificar qual a situação do uso das mídias digitais no processo de ensino-aprendizagem.

Para os alunos com idade menor que 18 anos foi entregue, uma semana antes da aplicação da pesquisa, um termo de livre consentimento para que os pais assinassem, autorizando a participação destes alunos na pesquisa.

Todos os questionários foram aplicados em papel impresso, conforme modelo Apêndice A e B, e durante o período de aula normal da escola, pois dificultaria a retirada dos alunos e dos professores da sala de aula para um laboratório de informática somente para responder a pesquisa. 
A pesquisa de campo foi realizada no mês de novembro de 2015. Foi respondida por 66 entrevistados, sendo 20 professores e 46 alunos.

\section{Pesquisa realizada com os professores}

Uma questão importante relatada por Dannemann (2013) versa sobre a atuação humana como mediadora no uso das mídias digitais em sala de aula para que, de fato, aconteça o propósito do ensino-aprendizagem, bem como a capacitação dos professores para a utilização das novas mídias digitais.

Segundo Dannemann (2013, p. 40),

É o professor quem compreende os alunos e sabe reconhecer as melhores maneiras de se aplicar este ou aquele recurso em sala de aula. Para tanto, é essencial que ele domine os conteúdos, as metodologias e as ferramentas, e conheça suas turmas de perto. Vale observar também que, por mais que estejam disponíveis, as informações da rede global de computadores não se transformam em conhecimento útil sem a participação de uma pessoa orientando e mediando para que aconteça o ensino, cujo propósito é a aprendizagem. Ou seja, parece repetitivo, mas é necessário voltar a valorizar a importância e a competência de um bom professor e a relevância de prepará-lo para utilizar novos recursos.

Todos os professores responderam que possuem acesso à internet e 55\% dos professores entrevistados disseram ficar conectados de 0 a 3 horas por dia; $42 \%$ dos professores disseram que a acessam a internet com mais frequência em suas casas.

Entre os professores entrevistados das duas escolas, $45 \%$ eram do sexo masculino e $55 \%$ do sexo feminino.

A distribuição obtida por faixa etária foi de 5\% da amostra com mais de 60 anos, $10 \%$ entre 50 e 59 anos, $20 \%$ entre 40 e 49 anos, $45 \%$ ente 30 e 39 anos e os $20 \%$ restantes correspondiam a entrevistados entre 20 e 29 anos.

Percebeu-se que a faixa etária dos professores que é mais abrangente (45\%) é compreendida entre as idades 30 e 39 anos.

Referente à formação acadêmica dos professores entrevistados, observa-se que $10 \%$ da amostra possui mestrado, $65 \%$ possui especialização, $25 \%$ possui graduação. Nenhum professor entrevistado possui doutorado.

Em relação à utilização da tecnologia em sala de aula como auxílio no ensinoaprendizagem, a maioria dos professores dessa amostra disseram que utilizam alguma tecnologia em sala de aula, conforme demonstrado no Gráfico 1. 
Gráfico 1: Utilização da tecnologia em sala de aula

\section{Você utiliza alguma tecnologia em sala de aula como recurso para auxilio no ensino-aprendizagem?}

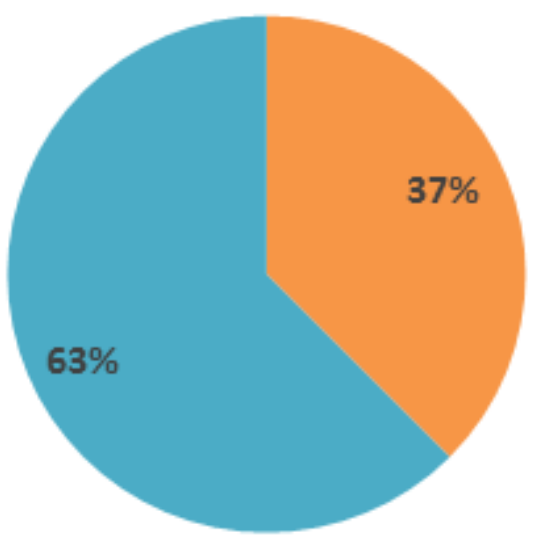

\section{Particular Pública}

Fonte: Elaboração própria.

Quando perguntados quais os recursos tecnológicos que os professores utilizavam em suas atividades em sala de aula, as opções mais assinaladas foram apresentações em Power Point e/ou Prezi e vídeos, conforme pode-se perceber no Gráfico 2.

Gráfico 2: Recursos tecnológicos utilizados em sala de aula

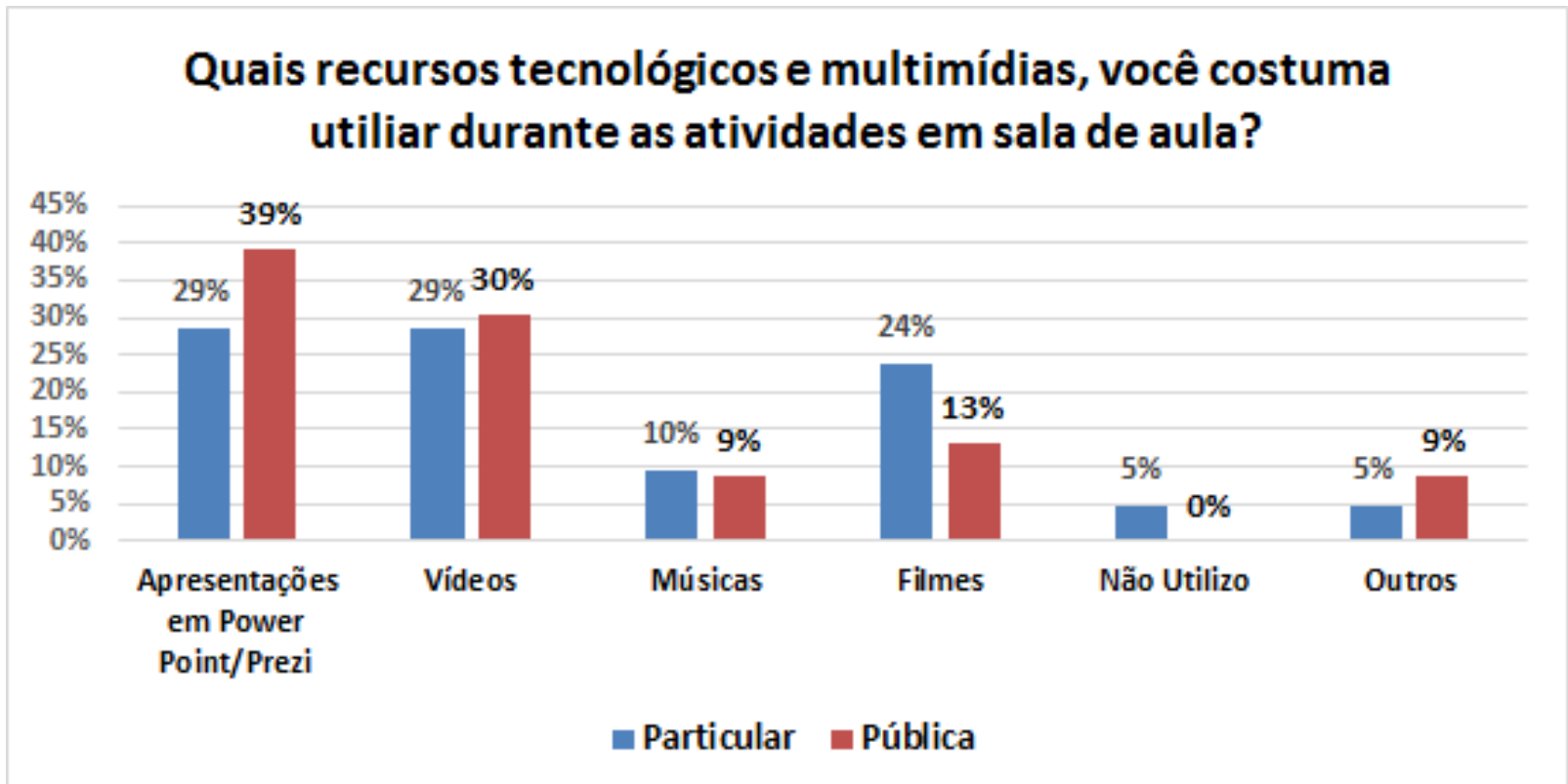

Fonte: Elaboração própria. 
Os professores também responderam a questão relacionada aos benefícios percebidos com a utilização do uso da tecnologia em suas atividades.

Pode-se perceber que os professores acreditam que são vários os benefícios percebidos com o uso da tecnologia em sala de aula, tais como: facilidade do entendimento do conteúdo, maior participação dos alunos, qualidade do conteúdo e interatividade. Tanto na escola particular como na pública as respostas foram similares.

Na pesquisa realizada com os professores destacou-se os seguintes percentuais:

- $90 \%$ disseram que se sentem qualificados para utilizar a tecnologia em sala de aula;

- $80 \%$ disseram que utilizam algum tipo de tecnologia em suas atividades durante as aulas, como recurso para auxiliar no ensino-aprendizagem;

- $34 \%$ utilizam mais as apresentações em Power Point;

- $65 \%$ utilizam as mídias digitais/tecnologia dentro da própria sala de aula, ou seja, raramente utilizam os laboratórios de informática disponíveis em ambas as escolas participantes da pesquisa.

Quando perguntado aos professores sobre o que entendem por mídias digitais, 47\% responderam que são as redes sociais (Facebook, Instagram, entre outros) e 37\% disseram que entendem que são os computadores, tablets, celulares, internet, entre outros.

O que demonstra que ainda não está bem definido para os professores, e talvez para as pessoas no geral, o que são as mídias digitais.

\section{Análise da pesquisa realizada com os alunos}

Com relação aos alunos entrevistados nas duas escolas, $43 \%$ eram do sexo masculino e $57 \%$ do sexo feminino.

A distribuição obtida por faixa etária foi de 33\% da amostra com 17 anos, 26\% com 15 anos, $24 \%$ com 18 anos, 9\% com 19 anos, 7\% com 16 anos e 2\% restantes correspondiam a entrevistados com 14 anos.

Pode-se perceber que a faixa etária dos alunos mais abrangente é a de 17 anos, com $33 \%$ dos respondentes. 
Com relação ao local de acesso à internet, 53\% dos alunos da amostra responderam que acessam a internet com maior frequência de casa, 27\% utilizam o smartphone e tablet, $13 \%$ acessam com maior frequência a internet da escola e $7 \%$ da casa de amigos/parentes, conforme apresentado no Gráfico 3 (abaixo).

Gráfico 3: Perfil da Amostra, segundo o local de acesso à internet com maior frequiência

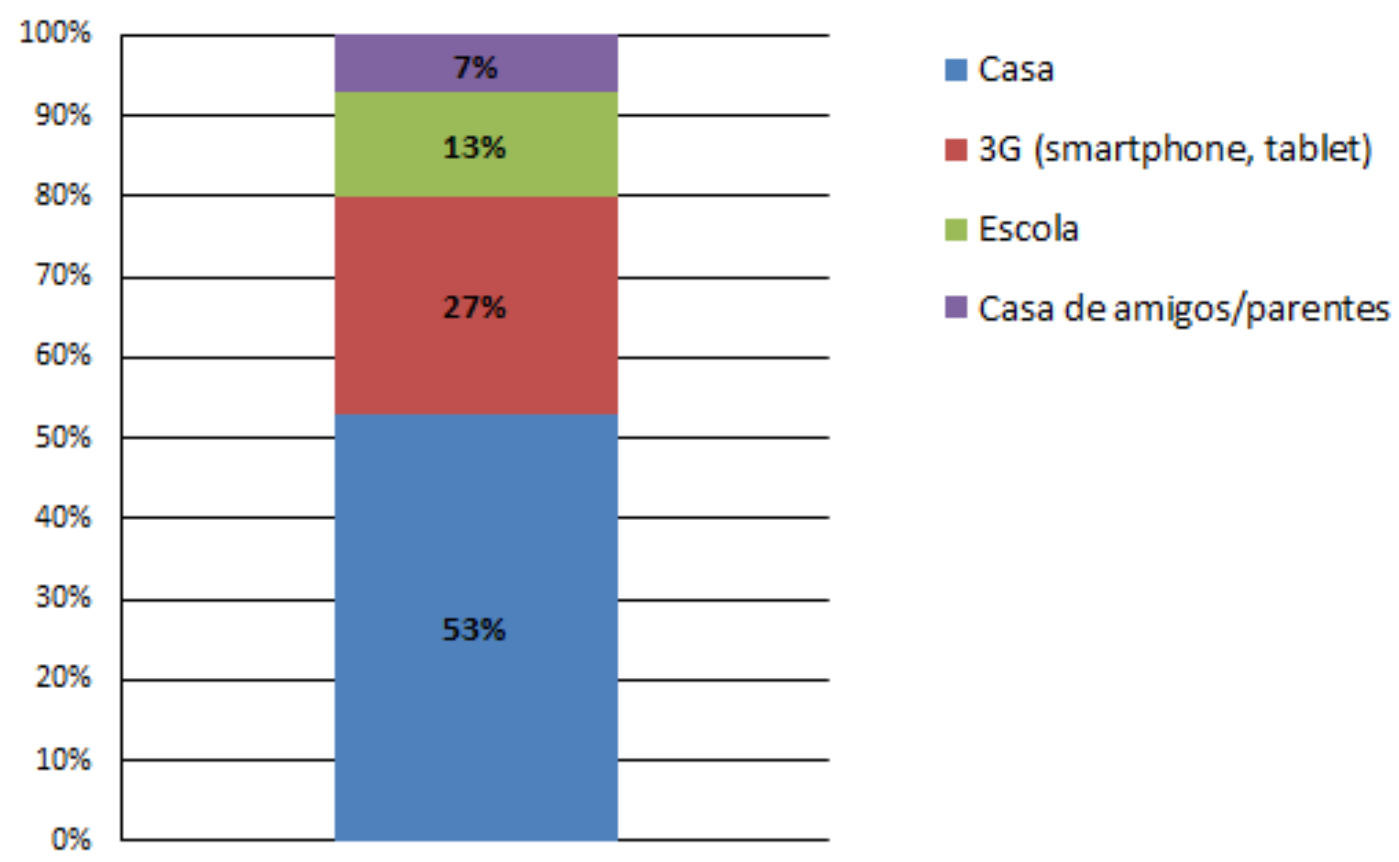

Fonte: Elaboração própria.

Quanto à quantidade de horas diárias de conexão, 35\% dos alunos da amostra responderam que acessam a internet mais de 10 horas por dia, 35\% acessam de 3 a 6 horas diárias, $23 \%$ de 6 a 10 horas por dia e $6 \%$ responderam que acessam de 0 a 3 horas diariamente.

Nesta parte do questionário perguntou-se: "Quais dispositivos você utiliza para acessar a internet?", em que os alunos entrevistados podiam responder mais de uma alternativa para essa questão. $40 \%$ responderam que utilizam o smartphone para acessar a internet, $25 \%$ utilizam o notebook, $22 \%$ utilizam o computador, $6 \%$ utilizam o tablet e $7 \%$ utilizam a smartTV, conforme demonstrado abaixo no Gráfico 4. 
Gráfico 4: Perfil da Amostra, segundo o dispositivo utilizado para acessar à internet

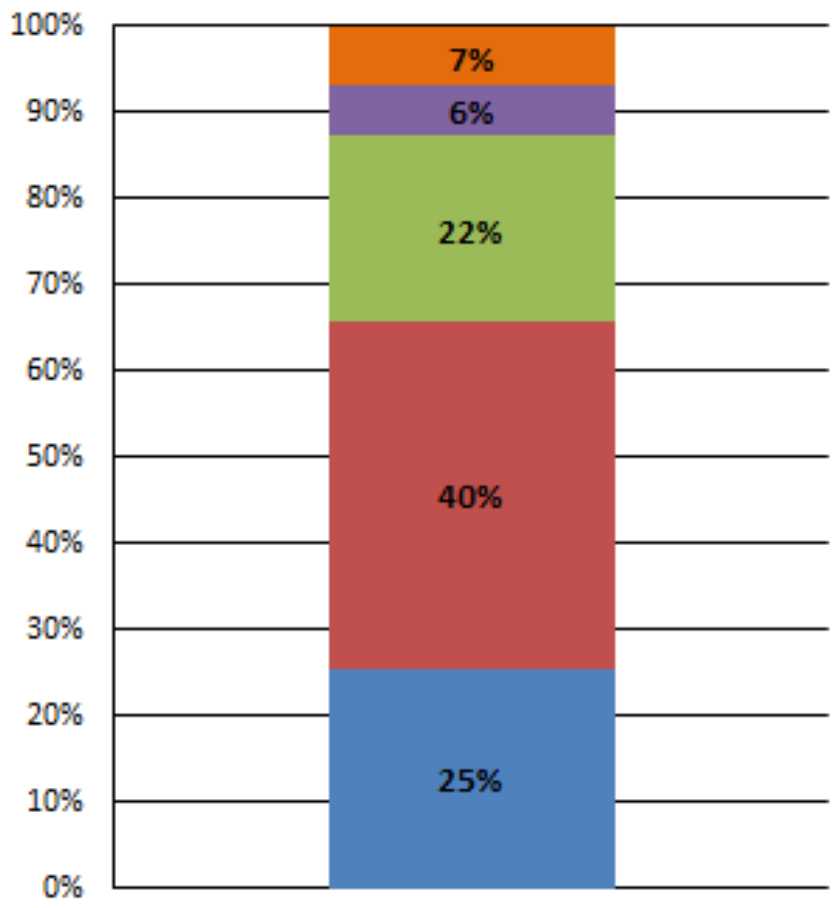

\author{
Notebook \\ Smartphone \\ computador \\ Tablet
}

SmartTV

Fonte: Elaboração própria.

Para observarmos qual o uso que os alunos da amostra fazem da internet, questionou-se "Para que você costuma utilizar a internet?". Nesta questão os entrevistados podiam assinalar mais de uma alternativa.

Percebeu-se que o resultado ficou bastante disperso, pois observa-se que $17 \%$ utilizam para conversar com amigos/parentes, 16\% utilizam para realizar trabalhos escolares e acessar as redes sociais, 14\% utilizam para assistir vídeos, $12 \%$ para ouvir músicas, $11 \%$ para notícias, $8 \%$ para jogar e 5\% para ler algum livro.

Na questão “Quais os sites que você utiliza para realizar pesquisas escolares?”, os entrevistados podiam assinalar mais de uma alternativa. O resultado obtido foi que 43\% utilizam sites ou portais especializados em conteúdos educativos, tais como: Infoescola e Khan Academy, por exemplo; 26\% utilizam a Wikipédia, 14\% utilizam textos acadêmicos, outros $14 \%$ disseram utilizar sites de streaming de vídeos, como, por exemplo, Youtube, e 3\% utilizam blog ou sites pessoais.

Questionou-se aos alunos sobre "Quais recursos tecnológicos e multimídias seus professores costumam utilizar durante as atividades em sala de aula?". Os entrevistados podiam assinalar mais de uma alternativa para essa questão.

Os alunos apontaram que o recurso mais utilizado durante as aulas pelos professores é o Power Point (37\%), depois a utilização de filmes (24\%), 23\% utilizam 
vídeos e os $16 \%$ restantes costumam utilizar músicas durantes as atividades em sala de aula.

Com relação aos benefícios percebidos pelos alunos no uso das tecnologias nas atividades em sala de aula, solicitou-se que os alunos respondessem como "Você percebe que o uso da tecnologia traz benefícios nas atividades em sala de aula?". Nesta questão os entrevistados também podiam assinalar mais de uma alternativa.

Observamos que $35 \%$ dos alunos disseram que o uso da tecnologia facilita o entendimento do conteúdo, $28 \%$ disseram que o conteúdo da disciplina fica mais interessante, $21 \%$ responderam que oferece maior participação/interesse dos alunos, $14 \%$ disseram que melhora a comunicação entre alunos e professores e somente $2 \%$ da amostra disseram que não traz benefícios.

Buscando compreender a visão dos alunos sobre seu conhecimento das "mídias digitais", uma das questões do questionário era "O que você entende por mídias digitais?". Os entrevistados podiam assinalar mais de uma alternativa para essa questão.

Percebe-se que: $41 \%$ dos alunos entrevistados entendem que as mídias digitais são os computadores, tablets, celulares e internet, $33 \%$ entendem que são as redes sociais, 23\% consideram mídias digitais os aplicativos (Microsoft Word, Excel e Power point) e $3 \%$ não quiseram arriscar nenhuma das alternativas.

Nesta parte do questionário foi perguntando "Quais os tipos de aplicativos você utiliza com mais frequência?". Os entrevistados podiam assinalar mais de uma alternativa para essa questão.

O resultado foi que $48 \%$ utilizam com mais frequência as redes sociais, e-mails e chats, $18 \%$ utilizam os editores de textos, $15 \%$ editor de imagens, $14 \%$ utilizam aplicativos para desenvolvimento de apresentações de slides, $2 \%$ utilizam editor de gráficos e planilhas e outros $2 \%$ para desenvolvimento de blogs.

$\mathrm{Na}$ questão "O que se entende por utilizar mídias/computador no ensinoaprendizagem?", os entrevistados podiam assinalar mais de uma alternativa para essa questão.

Demonstrou-se que $49 \%$ acreditam que as mídias/computadores são ferramentas que podem contribuir grandemente para o ensino-aprendizagem, $31 \%$ acham que é mais um recurso extra para ser utilizado durante as aulas, $15 \%$ acham que é um meio de ensinar e 5\% acham que é apenas um elemento de consulta. 


\section{Análise geral das características das mídias digitais nas escolas}

A pesquisa aplicada aos alunos foi dividida em 3 partes: características pessoais, perfil do aluno e perfil da escola.

Foram desenvolvidas e aplicadas 6 questões relacionadas ao perfil do aluno e ao contato deste aluno com a internet, e 8 questões relacionadas ao uso das mídias digitais/tecnologia em sala de aula.

Já o questionário que foi aplicado aos professores foi dividido em 2 partes: características pessoais e características gerais.

Para os professores foram utilizadas 20 questões para investigar o uso das mídias digitais/tecnologia em suas atividades durante as aulas.

O jovem estudante, delimitado nesta pesquisa, é predominantemente da faixa etária de 14 a 19 anos e os professores delimitados, que predominam na pesquisa, possuem a faixa etária entre 20 a 49 anos.

Referente ao gênero, o percentual maior é o feminino, tanto quando fala-se dos professores quanto dos alunos entrevistados (55\% e 57\%, respectivamente).

Todos os alunos pesquisados estão cursando o ensino médio no período matutino. E todos os professores que participaram da pesquisa lecionam no ensino médio.

Na pesquisa realizada pela cetic.br em 2013, constatou-se o aumento do uso da internet no interior dos domicílios. Foi possível observar que o local de acesso à internet em maior destaque é a sala de casa, com $68 \%$, e, na pesquisa que realizamos, $53 \%$ dos alunos da amostra responderam que acessam a internet com maior frequência de casa. Este é um dado que teve alta similaridade quando comparadas as duas pesquisas.

Percebe-se no Gráfico 5, portanto, o aumento do uso da internet no interior dos domicílios; com isso, os centros públicos de acesso pago à rede, como lan houses e cybercafés, tiveram decréscimo significativo: passando de $35 \%$ em 2012 para $22 \%$ em 2013, como pode ser observado no gráfico abaixo. 
Gráfico 5: Local de acesso à internet

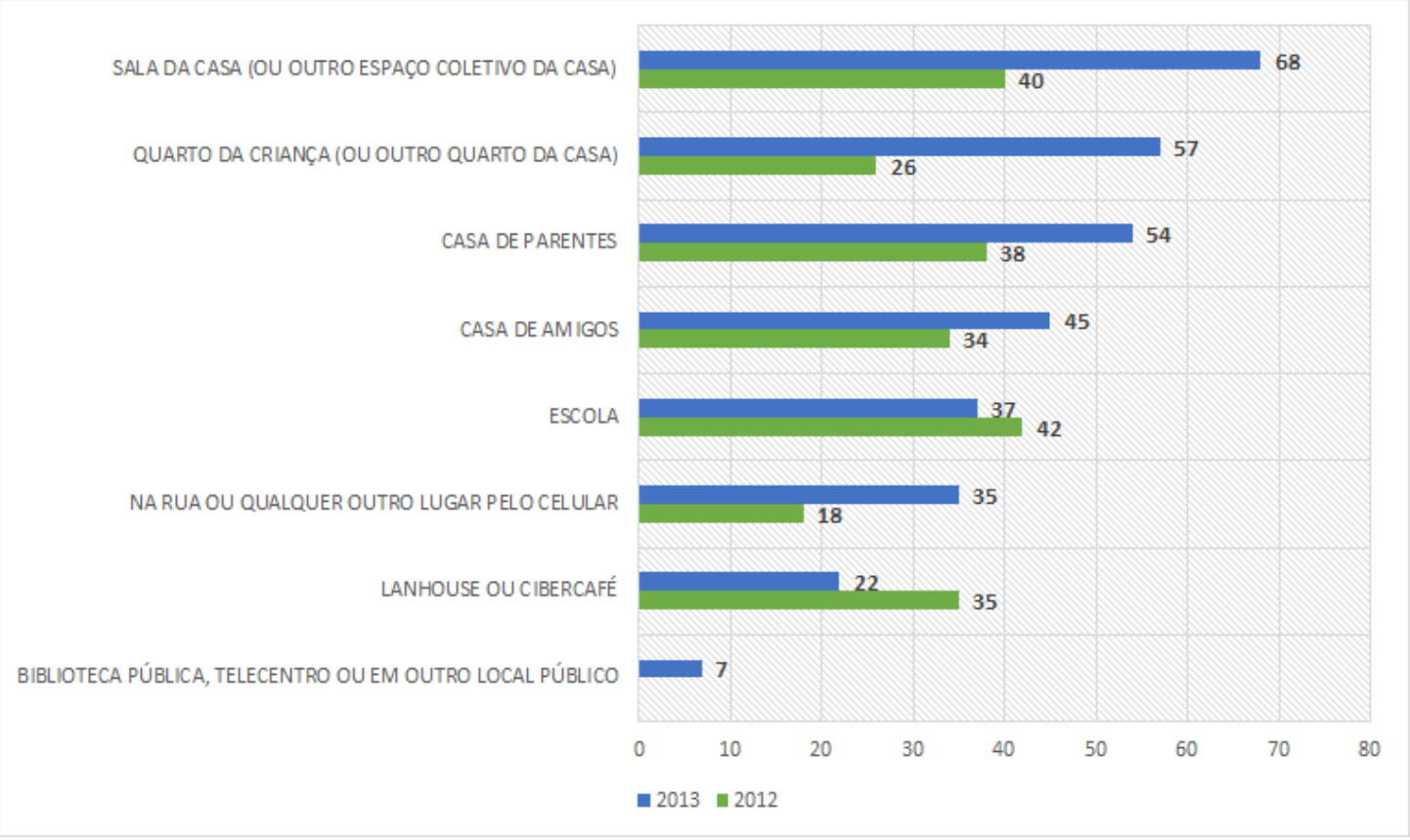

Fonte: Adaptado pela autora a partir da pesquisa Tic kids online, 2013.

Já quando se trata do acesso à internet nas escolas, este é um percentual que preocupa. Na pesquisa da cetic.br, considerando os anos de 2012 e 2013, o percentual de acesso diminuiu $42 \%$ e $37 \%$, respectivamente, e na pesquisa que realizamos tem-se a diminuição de $13 \%$. Percebe-se, pelos dados do cetic.br e pela pesquisa realizada, que a tendência de redução ao acesso persiste.

A suposição inicial era de que a escola poderia (deveria) ser um local de maior acessibilidade à internet e à mídia digital, para incentivar os alunos, que são nativos digitais, a buscar conteúdos educativos.

Quando se trata da frequência de uso da internet, notou-se que na frequência de acesso dos jovens,com idade entre 15 e 17 anos, o percentual apresentado pela pesquisa realizada pelo cetic.br é de $74 \%$ em 2013, o que demonstra que o jovem acessa a internet todos os dias ou quase todos os dias.

Entre os jovens estudantes das escolas pesquisadas neste trabalho foi notado que $35 \%$ acessam a internet mais de 10 horas por dia e 35\% acessam de 3 a 6 horas diárias.

Pode-se, portanto, perceber que os jovens e adolescentes nas faixas etárias mais elevadas navegam na rede com maior frequência, o que fortalece sua experiência e cultura digital. 
Quando se comparou os dados da pesquisa do cetic.br e os dados da nossa pesquisa, encontrou-se outra diferença. Neste levantamento de dados questionou-se para que esses adolescentes costumavam utilizar a internet.

Nos dados apontados pelo cetic.br, $87 \%$ das crianças e adolescentes, no ano de 2013, afirmaram que utilizam a internet para trabalhos escolares. Já os dados apontados na pesquisa que realizamos observou-se que apenas $16 \%$ utilizam a internet para realizar trabalhos escolares, uma diferença grande entre as duas pesquisas.

Outra similaridade encontrada entre a pesquisa realizada pelo cetic.br e a pesquisa que realizamos foi referente ao dispositivo utilizado pelos adolescentes para acessar a rede, pois na pesquisa realizada pelo cetic.br de 2014, o uso do dispositivo smartphone apresentou o percentual de $82 \%$, e na pesquisa que realizamos, alunos das duas escolas demonstraram que $40 \%$ usam com mais frequência o smartphone.

De acordo com pesquisas mais recentes realizadas pelo cetic.br, este índice tem aumentado com o passar dos anos, demonstrando que houve um crescimento significativo do uso do smartphone pelos adolescentes.

\section{Considerações finais}

Durante o desenvolvimento desta proposta de pesquisa, foi possível aprofundar algumas definições de mídias digitais (computadores, tablets, internet, etc), e pensar como esses dispositivos tecnológicos podem auxiliar para melhorar o ensinoaprendizagem nas instituições de ensino, além de possibilitar compreender um pouco mais sobre o perfil dos nativos digitais.

De acordo com Bariani (2011), há uma grande discrepância entre o papel interativo do indivíduo desempenhado fora das salas de aula em meio aos ambientes virtuais (os adolescentes que nasceram e cresceram com a tecnologia do século 21, "nativos digitais") e entre o posicionamento usualmente passivo ao qual o estudante é condicionado (em sala de aula).

Segundo Lutz (2014), as novas tecnologias, em especial na área da informática, estão cada vez mais presentes no cotidiano dos alunos, sendo que aqueles que não se adaptarem a essa realidade correm o risco de serem considerados analfabetos tecnológicos. Para evitar tal situação, as escolas, com a responsabilidade de preparar e 
desenvolver este aluno para atuar como cidadão crítico e ativo na sociedade, começam a observar a necessidade de seguir o ritmo do desenvolvimento tecnológico.

Com esta pesquisa, constatou-se que todos os entrevistados (alunos e professores) possuem acesso à internet de alguma forma, e as mídias digitais utilizadas com maior frequência por eles são smartphones, computadores e internet, assim como a pesquisa da cetic.br constatou que os equipamentos mais utilizados para acessar a internet são os computadores de mesa, PC, desktop, com 38\% em 2012 e $71 \%$ no ano de 2013; observou também aumento no percentual de dispositivos como o celular (smartphone) e o tablet.

A pesquisa que realizamos nas escolas de Bauru/SP demonstrou que os recursos tecnológicos mais utilizados em sala de aula durante as atividades ainda são as apresentações em Power Point.

A pesquisa realizada pela cetic.br demonstra um dado importante sobre o uso do computador e da internet durante as aulas, indicando um aumento, partindo de $24 \% \mathrm{em}$ 2010 para $48 \%$ em 2013, e na nossa pesquisa também pode-se perceber que os professores utilizam a internet e recursos tecnológicos durante as atividades em sala de aula.

Conforme pode-se perceber quando os professores responderam sobre os recursos tecnológicos utilizados em sala de aula durante suas atividades, quase todos indicaram que utilizam alguma mídia digital/tecnologia (apresentações em Power Point e/ou Prezi, músicas, filmes ou vídeos).

O aumento do percentual na utilização do computador e internet na realização de atividades com os alunos é perceptível tanto na pesquisa realizada pela cetic.br quanto na pesquisa que realizamos.

Pode-se inferir pelos dados estudados do Comitê Gestor da Internet no Brasil (2012 e 2013) e levantados na pesquisa junto à comunidade acadêmica (professores e alunos), que tal público está ciente dos benefícios que a mídia digital/tecnologia traz para as salas de aula, destacando a facilidade de entendimento do conteúdo e a contribuição da mídia digital/tecnologia para o ensino-aprendizagem.

Como sugestão, e com base nos resultados da pesquisa realizada, é interessante que as escolas pesquisadas comecem a ter um olhar voltado para utilização da mídia digital/tecnologia durante as atividades acadêmicas, envolvendo os alunos e professores, que, conforme apontado nos resultados, estão inseridos no mundo digital. 
Ficou bem definido que os jovens estudantes utilizam com frequência e em grande quantidade de horas por dia a mídia digital/tecnologia, seja para conversas, trabalhos escolares, notícias, ouvir músicas ou assistir filmes. Isso demonstra que esses jovens, os nativos digitais, utilizam as mídias digitais/tecnologias para tudo.

Baseados nos conceitos apresentados neste trabalho deduzimos que a educação brasileira apresenta grandes possibilidades, além dos desafios existentes, para fomentar a educação no século XXI, com o uso criativo das mídias digitais/tecnologias disponíveis, como apoio no ensino-aprendizagem.

Estamos cientes que esta pesquisa representa o início de um caminho a ser trilhado. Sabemos que é preciso explorar e buscar se aprofundar mais sobre os assuntos abordados neste trabalho, pois a continuidade da pesquisa poderia nos oferecer uma visão sistêmica do perfil dos nativos digitais relacionado às mídias digitais/tecnologia e ao sistema educacional que estão inseridos.

AGRADECIMENTOS: Coordenação de Aperfeiçoamento de Pessoal de Nível Superior.

\section{REFERÊNCIAS}

BARIANI, B. B.; Hipermídia e Educomunicação: o papel das novas mídias digitais no ensino, Revista Sessões do Imaginário, Ano XVI, no. 25, janeiro de 2011.

CASTELLS, M. (1999) Sociedade em Rede. São Paulo: Paz e Terra.

Comitê Gestor da Internet no Brasil - cgi.br (2013) Pesquisa sobre o uso das tecnologias de informação e comunicação nas escolas Brasileiras - TIC educação. Disponível em: <http://cetic.br/media/docs/publicacoes/2/tic-educacao-2013.pdf>. Acesso em: 10 nov. 2015.

Comitê Gestor da Internet no Brasil - cgi.br (2013) Pesquisa sobre o uso da Internet por crianças e adolescentes no Brasil - TIC Kids Online Brasil 2013. Disponível em: <http://cetic.br/media/docs/publicacoes/2/tic-kids-online-2013.pdf>. Acesso em: 21 jan. 2016.

DANNEMANN, A. C. In: O desafio do uso da tecnologia na prática da sala de aula. São Paulo: Comitê Gestor da Internet no Brasil. Disponível em: <http://cetic.br/media/docs/publicacoes/2/tic-educacao-2012.pdf >. Acesso em: 10 nov. 2015. 
DARIDO DA CUNHA, M.; BIZELLI, J. L. Caminhos para TIC em sala de aula sob a perspectiva dos professores. Revista on line de Política e Gestão Educacional, Araraquara, v. 20, n. 2, p. 282-300, 2016. Disponível em: <http://dx.doi.org/10.22633/rpge.v20.n2.9458>. ISSN: 1519-9029.

LUTZ, M. R.; Utilização de mídias digitais como metodologia de ensinoaprendizagem de matemática, PROJETO DE CURTA DURAÇÃO, Instituto Federal de Farroupilha, Campus Alegrete, 2014.

MARTINO, L, M. S. Teoria das mídias digitais: linguagens, ambientes, redes. Petrópolis, RJ: Vozes, 2014.

PERRENOUD, P. Construir as competências desde a escola. Porto Alegre: Artmed, 1999.

PFROMM NETTO, S. Telas que ensinam - mídia e aprendizagem: do cinema às tecnologias digitais. Campinas, SP: Editora Alínea, 2011

ROCHA, Rozane de Fátima Zaionz da.; MOREIRA, Herivelto. Escolas públicas do município de Curitiba: as novas tecnologias nas escolas de tempo integral. Revista Ibero-Americana de Estudos em Educação, Araraquara, v.12, n. 1, p. 350-370, 2017. Disponível em: <http://dx.doi.org/10.21723/riaee.v12.n1.8476>. E-ISSN: 19825587.

\section{Como referenciar este artigo}

BITTENCOURT, Priscilla Aparecida Santana.; ALBINO, João Pedro. Reflexão sobre a utilização criativa dos recursos tecnológicos. Revista on line de Política e Gestão Educacional, Araraquara, v.21, n. esp. 1, p. 691-705, out./2017. Disponível em: <http://dx.doi.org/10.22633/rpge.v21.n.esp1.out.2017.10448>. ISSN: 1519-9029.

Submetido em: 10/03/2017

Aprovado em: 25/08/2017 